\title{
An amino acid-electrolyte beverage may increase cellular rehydration relative to carbohydrate-electrolyte and flavored water beverages
}

Chih-Yin Tai ${ }^{1}$, Jordan M Joy ${ }^{1}$, Paul H Falcone ${ }^{1}$, Laura R Carson ${ }^{1}$, Matt M Mosman', Justen L Straight ${ }^{2}$, Susie L Oury ${ }^{3}$, Carlos Mendez $\mathrm{Jr}^{3}$, Nick J Loveridge ${ }^{1,4}$, Michael P Kim ${ }^{1}$ and Jordan R Moon ${ }^{1,5^{*}}$

\begin{abstract}
Background: In cases of dehydration exceeding a $2 \%$ loss of body weight, athletic performance can be significantly compromised. Carbohydrate and/or electrolyte containing beverages have been effective for rehydration and recovery of performance, yet amino acid containing beverages remain unexamined. Therefore, the purpose of this study is to compare the rehydration capabilities of an electrolyte-carbohydrate (EC), electrolyte-branched chain amino acid (EA), and flavored water (FW) beverages.

Methods: Twenty men $(n=10 ; 26.7 \pm 4.8$ years; $174.3 \pm 6.4 \mathrm{~cm} ; 74.2 \pm 10.9 \mathrm{~kg})$ and women $(n=10 ; 27.1 \pm 4.7$ years; $175.3 \pm 7.9 \mathrm{~cm} ; 71.0 \pm 6.5 \mathrm{~kg}$ ) participated in this crossover study. For each trial, subjects were dehydrated, provided one of three random beverages, and monitored for the following three hours. Measurements were collected prior to and immediately after dehydration and 4 hours after dehydration ( 3 hours after rehydration) ( $A E=-2.5 \pm 0.55 \%$; $\mathrm{CE}=-2.2 \pm 0.43 \% ; \mathrm{FW}=-2.5 \pm 0.62 \%)$. Measurements collected at each time point were urine volume, urine specific gravity, drink volume, and fluid retention.

Results: No significant differences ( $p>0.05$ ) existed between beverages for urine volume, drink volume, or fluid retention for any time-point. Treatment $x$ time interactions existed for urine specific gravity (USG) $(p<0.05)$. Post hoc analysis revealed differences occurred between the FW and EA beverages $(p=0.003)$ and between the EC and EA beverages $(p=0.007)$ at 4 hours after rehydration. Wherein, EA USG returned to baseline at 4 hours post-dehydration (mean difference from pre to 4 hours post-dehydration $=-0.0002 ; p>0.05)$ while both EC $(-0.0067)$ and FW $(-0.0051)$ continued to produce dilute urine and failed to return to baseline at the same time-point $(p<0.05)$.

Conclusion: Because no differences existed for fluid retention, urine or drink volume at any time point, yet USG returned to baseline during the EA trial, an EA supplement may enhance cellular rehydration rate compared to an EC or FW beverage in healthy men and women after acute dehydration of around $2 \%$ body mass loss.
\end{abstract}

Keywords: Rehydration, Fluid retention, Amino acid, Carbohydrate, Electrolyte, Hydration, Recovery

\footnotetext{
*Correspondence: jordan@musclepharm.com

${ }^{1}$ MusclePharm Sports Science Institute, MusclePharm Corp., 4721 Ironton St.,

Building A, Denver, CO 80239, USA

${ }^{5}$ Department of Sports Exercise Science, United States Sports Academy,

Daphne, AL, USA

Full list of author information is available at the end of the article
}

C Biomed Central
(C) 2014 Tai et al.; licensee BioMed Central Ltd. This is an Open Access article distributed under the terms of the Creative Commons Attribution License (http://creativecommons.org/licenses/by/4.0), which permits unrestricted use, distribution, and reproduction in any medium, provided the original work is properly credited. The Creative Commons Public Domain Dedication waiver (http://creativecommons.org/publicdomain/zero/1.0/) applies to the data made available in this article, unless otherwise stated. 


\section{Background}

In conditions of elevated body temperature, the body can dissipate heat through either convection, conduction, radiation, or evaporation. However as temperature rises, the effectiveness of convection and conduction decreases and radiation becomes insignificant [1,2]. This creates a concomitant increase in dissipation through evaporation, accounting for up to $98 \%$ of cooling [1]. Thus, evaporation of sweat is the body's primary mechanism for decreasing body temperature. Without replacement of fluids, an athlete can quickly become dehydrated during training or competition.

Robust fluid loss (5-10\% of body weight) can be well tolerated by healthy individuals at rest [3], yet a $2-3 \%$ fluid loss impairs exercise performance [3-11]. In a study by Armstrong et al. [4], competitive runners were tested in time trials of varying distances as well as time to exhaustion under conditions of hydration and dehydration in a crossover design. Dehydrated athletes took longer to complete each time trial and experienced a decreased time to exhaustion. In a hot, humid environment, performance decrements can be further exacerbated by dehydration [12,13]. While athletes may adequately recover fluids lost with multiple days separating exercise sessions, those who partake in practice or competition daily or twice-per-day must utilize strategies to recover fluids lost as soon as possible after an exercise bout.

Water may typically be used by athletes to rehydrate, yet nearly every rehydration trial has determined water to be inadequate for rapid recovery of lost body fluids [14-20]. This is persistent even when high volumes of water are consumed due to the concomitant decrease in sodium concentration creating a hyponatremic state. However, simply adding sodium to water increases rehydration and better restores exercise performance [21], and the same observations are reported when adding sodium to milk [22] and coconut water [20]. The importance of sodium for rehydration is well established [23,24], yet evidence supporting potassium and carbohydrate are less robust.

Sodium is the major electrolyte of the extracellular space and is the primary ion lost in sweat [25], yet potassium is the primary intracellular electrolyte and has also indicated efficacy in rehydration [26,27]. Maughan and colleagues [28] have demonstrated equal fluid retention after consumption of sodium or potassium containing beverages administered after exercise induced dehydration. While supplementation with carbohydrates can directly benefit performance [18], they also assist in the rehydration process, though primarily through increased palatability $[29,30]$. In a similar fashion, proteins further increase rehydration when added to a carbohydrate- electrolyte (CE) beverage. Seifert et al. [16] compared the rehydration capabilities of a $\mathrm{CE}$, protein-CE, and plain water beverage following a dehydration protocol. They observed that the addition of protein to a CE beverage resulted in greater increases in fluid retention and plasma volume compared to the $\mathrm{CE}$ and plain water beverages. However in addition to greater protein content, there was also a greater presence of electrolytes, notably $44 \%$ more potassium than the $\mathrm{CE}$ beverage. Similar findings have been noted when examining the protein containing beverage milk, which also has a greater presence of electrolytes $[19,22]$. Whether the increased fluid retention in these studies are due to additional protein or electrolytes remains ambiguous. However, protein can stimulate muscle protein synthesis and aid in glycogen resynthesis when carbohydrate intake is inadequate [31]. Thus while sodium is an important component of a rehydration beverage, the importance of potassium and other solutes, such as carbohydrate and protein, is not to be overlooked.

While protein is capable of increasing muscle protein synthesis, it is primarily the branched chain amino acids (BCAA) which drive this process, namely leucine $[32,33]$. Therefore, it is conceivable that if the addition of protein to a $C E$ beverage may enhance rates of rehydration, the addition of its constituents, such as BCAAs, may enhance rehydration as well. In any event, they would surely benefit recovering muscle tissue and may be recommended for post-exercise consumption. However, the effects of BCAA's on rehydration remains to be investigated. Additionally, previous research has administered test beverages in very large quantities, which are not practical for most athletes. Therefore, the purpose of this study was to compare the rehydrating effects of a BCAA-electrolyte (AE) beverage, $\mathrm{CE}$, and flavored water (FW) control on exercise-induced dehydration and also to determine if a modest, more practical amount of these beverages in combination with water to compose the additional fluid requirement would provide adequate rehydration. We hypothesized the $\mathrm{AE}$ and $\mathrm{CE}$ beverages would rehydrate similarly, yet they would rehydrate to a greater extent compared to the FW beverage.

\section{Methods}

\section{Subjects}

Twenty men $(\mathrm{n}=10 ; 26.7 \pm 4.8$ years; $174.3 \pm 6.4 \mathrm{~cm}$; $74.2 \pm 10.9 \mathrm{~kg})$ and women $(\mathrm{n}=10 ; 27.1 \pm 4.7$ years; $175.3 \pm 7.9 \mathrm{~cm} ; 71.0 \pm 6.5 \mathrm{~kg}$ ) participated in this study. Each subject was required to have a minimum of one year endurance and resistance training experience, be free of any cardiovascular, metabolic, renal, hepatic, musculoskeletal, or any other disorder which may affect study outcomes, be free of any medication, supplements, or pharmaceutical which may influence measurements. Prior to testing, the study was approved by the MusclePharm Sports Science Institute Institutional Review Board 
and all subjects provided written informed consent to participate in this study.

\section{Experimental design}

In a double blind design, subjects participated in each of three beverage trials in a randomized order. Each trial was separated by a washout period of at least 7 days. The contents and volume of drink consumed for each trial can be found in Tables 1 and 2. Baseline measurements were collected individually for each trial then repeated immediately and 4 hours post-dehydration. Following baseline measurements, subjects performed the dehydration and rehydration protocols. The rehydration period occurred during the hour immediately following post-dehydration measurements. All trials were conducted in the morning, and subjects were instructed to refrain from exercise for 24 hours, solid food consumption for 8 hours, and water consumption for 1 hour prior to each trial. Each subject's hydration status was assessed upon arrival by urine specific gravity (USG). In the event USG was greater than 1.025 , the subject was provided with $500 \mathrm{~mL}$ water in accordance with ACSM recommendations [34] to ensure all subjects began each trial in a euhydrated state. This occurred on only two occasions.

\section{Dehydration and rehydration}

Dehydration was achieved through a combination of exercise and sauna. To begin the dehydration protocol, each subject ran on a treadmill for 30 minutes at $80 \%$ of their estimated max heart rate $(206.9-0.67 \times$ age). Afterwards, subjects sat in a sauna at $70^{\circ} \mathrm{C}$ in 15 minute intervals such that about a $2 \%$ body weight loss was attained $(\mathrm{AE}=-2.5 \pm 0.55 \%$; $\mathrm{CE}=-2.2 \pm 0.43 \%$; $F W=-2.5 \pm 0.62 \%)$. Between sauna intervals, 2 minutes were dedicated to collecting subjects' nude, dry body weight. During rehydration, subjects were administered equal volumes of the $\mathrm{AE}$ (Amino1 ${ }^{\mathrm{mm}}$, MusclePharm Corp.),

Table 1 Composition and amount of test beverage administered

\begin{tabular}{llll}
\hline & AE & CE & FW \\
\hline Test Volume (mL) & $772.5 \pm 93.17$ & $774.7 \pm 100.9$ & $770.8 \pm 96.88$ \\
Calcium (mg) & $96.2 \pm 11.31$ & $7.9 \pm 1.00$ & $.2 \pm 0.02$ \\
Phosphorous (mg) & $116.3 \pm 13.67$ & $78.6 \pm 9.98$ & $.2 \pm 0.02$ \\
Magnesium (mg) & $400.8 \pm 47.12$ & 0 & 0 \\
Sodium (mg) & $80.2 \pm 9.43$ & $311.7 \pm 39.57$ & $1.2 \pm 0.14$ \\
Potassium (mg) & $200.5 \pm 23.57$ & $120.5 \pm 15.30$ & $121.3 \pm 14.86$ \\
BCAA (g) & $6.0 \pm 0.71$ & 0 & 0 \\
Carbohydrate (g) & $2.0 \pm 0.24$ & $52.4 \pm 6.65$ & $.4 \pm 0.05$ \\
Calorie (kcal) & $10.0 \pm 1.18$ & $207.0 \pm 26.27$ & $8.9 \pm 1.09$ \\
\hline
\end{tabular}

The total amount of solute present is provided. Data are presented as mean $\pm \mathrm{SD}$.
CE (Gatorade ${ }^{\mathrm{Tx}}$, Pepsi Corp.), or FW (Crystal Light ${ }^{\mathrm{Tm}}$, Kraft Foods Corp.) beverage immediately after dehydration testing. Initially, subjects were provided with $~ 30-35 \%$ of their total drink volume as test beverage. The amount of test beverage was determined primarily by the $\mathrm{AE}$ condition. Wherein, $0.25 \mathrm{~g}$ of amino acids per $\mathrm{kg}$ baseline body weight was the target for the $\mathrm{AE}$ condition, as this has been shown to positively influence nitrogen balance [35]. It also produced reasonable doses for all test beverages. After delivery of the test beverage, the remaining volume was equally divided into 3 doses of water provided over the final three 15 minute intervals such that total fluid ingestion occurred over a one hour period immediately after dehydration testing. The total volume of beverage administered was equal to $150 \%$ of fluid lost during dehydration [36]. Thus, the volume of water was determined as the calculated total volume minus the calculated test volume. Subjects were required to consume the entire volume of fluid in the allotted 1 hour rehydration period. Beverage composition can be found in Table 1 .

\section{Measurements}

Measurements for all trials were taken prior to, immediately following, and 4 hours following the dehydration protocol. At baseline and immediately post-dehydration, nude body weight and USG were assessed and subjects were instructed to empty their bladder completely. Subjects were instructed to report to the laboratory without voiding and upon arrival to void as much as possible into a collection jug. From this, USG was measured using a handheld refractometer (Atago, Tokyo, Japan). At 4 hours post-dehydration, the aforementioned variables were reassessed as well as total urine volume over the 4 hour rehydration period and fluid retention was calculated as total drink volume minus 4 hour total urine volume divided by total drink volume.

\section{Statistics}

All data were analyzed using SPSS software (Version 20.00, SPSS Inc., Chicago, Illinois, USA). A $3 \times 3$ repeated measures ANOVA was used to determine treatment by time interactions for USG and urine volume. A one-way ANOVA was used to determine differences in drink volume and fluid retention. A Bonferroni post-hoc analysis was used to locate differences.

\section{Results}

No significant differences $(\mathrm{p}>0.05)$ existed between beverages for percent body weight loss, drink volume (test or total), urine volume, or fluid retention for any time point (Table 2). Treatment $\mathrm{x}$ time interactions were observed for USG ( $p<0.05 ; \mathrm{F}=0.783$ ) (Figure 1). Post hoc analysis revealed differences occurred between the EA and FW 
Table 2 Dependent variables between treatments

\begin{tabular}{llll}
\hline & AE & CE & FW \\
\hline Total drink volume $(\mathrm{mL})$ & $2292.25 \pm 457.99$ & $2279.26 \pm 483.63$ & $2360.44 \pm 519.75$ \\
Test drink volume $(\mathrm{mL})$ & $772.46 \pm 93.17$ & $774.73 \pm 100.9$ & $770.83 \pm 96.88$ \\
Water drink volume $(\mathrm{mL})$ & $1519.79 \pm 388.04$ & $1504.52 \pm 428.92$ & $1589.62 \pm 476.92$ \\
Total urine volume $(\mathrm{mL})$ & $1295.5 \pm 457.56$ & $1348.25 \pm 450.94$ & $1363.25 \pm 520.44$ \\
Fluid retention $(\%)$ & $43.5 \pm 17.1$ & $40.8 \pm 18.1$ & $42.2 \pm 14.3$ \\
\hline
\end{tabular}

Data are presented as mean \pm SD. Fluid retention was calculated as: (Total Drink Volume - Total Urine Volume) / Total Drink Volume

beverages $(\mathrm{p}=0.003)$ and between the EA and EC beverages $(\mathrm{p}=0.007)$ at 4 hours after dehydration.

\section{Discussion}

The results of this study both partially agreed and disagreed with our hypotheses. The AE and CE beverages rehydrated about equally; however, they were also equal to the FW beverage. The purpose of this investigation was to compare the rehydration capabilities of $\mathrm{AE}, \mathrm{CE}$, and FW beverages. The primary finding of this study was USG for the AE condition at 4 hours returned to baseline following dehydration while CE and FW trials resulted in more diluted urine (lower USG values). Additionally, there were no significant interactions for percent body weight loss, urine volume, drink volume, or fluid retention for any condition. On the basis of these findings, it would appear that all conditions were equally capable of rehydration. However, because an

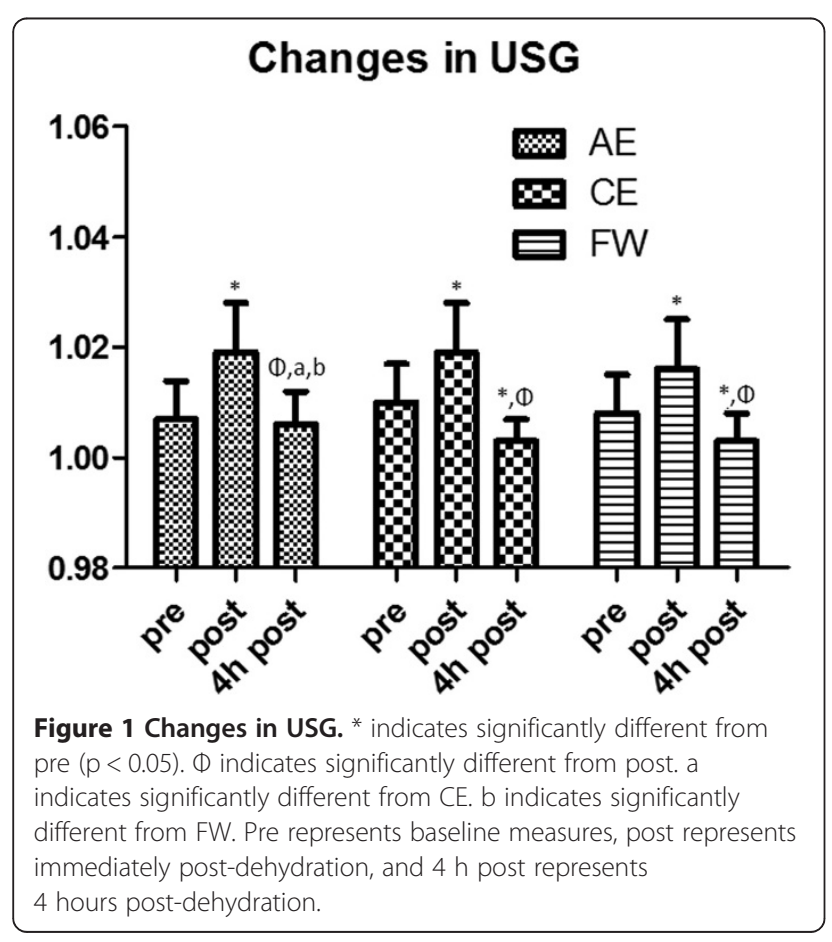

equal fluid retention was observed between all conditions, yet USG did not show the same decremented pattern (dilution at 4 hours) as $\mathrm{CE}$ or FW, it appears that the $\mathrm{AE}$ beverage increased intracellular hydration more favorably than either CE or FW since the urine was not as diluted at 4 hours in the AE trial with equal urine volume (Table 2). Thus at 4 hours post-dehydration, subjects experienced the same USG as pre-testing, while at the same time-point, CE and FW trials resulted in significantly lower USG values compared to pre-testing which suggests increased diuresis through urine and less cellular retention. Furthermore, based on the USG results, it is hypothesized that if urine volumes were collected beyond 4 hours post-dehydration (3 hours post rehydration) that both CE and FW would have resulted in greater urine volumes compared to $\mathrm{AE}$ and USG would eventually return to baseline. Since there was an apparent increase in water in the bladder at 4 hours post-dehydration for CE and FW and USG had not returned to baseline, the body may continue to shed water until USG returned to baseline. This hypothesis can be supported further by the reduced urine volume in the $\mathrm{AE}$ treatment compared to $\mathrm{CE}$ and FW as there was a trend at 4 hours post-dehydration for $\mathrm{AE}$ to retain more water (Table 2).

No significant interactions were observed between conditions for urine volume, drink volume, or fluid retention at any time point. These results are contradictory to those previously reported $[16,19,28]$. In each of these studies, greater electrolyte content produced greater fluid retention. A greater fluid retention was expected for the $\mathrm{AE}$ and $\mathrm{CE}$ conditions compared to the FW. However, it is possible that the $121.3 \mathrm{mg}$ of potassium in the FW condition was sufficient to produce insignificant results compared to the greater overall sodium and potassium content of the $\mathrm{AE}$ and $\mathrm{CE}$ conditions. In agreement with the present results, Mitchell and colleagues [37] examined 4 different relationships of drink volume and sodium concentration, and it was apparent that drink volume had a greater influence on rehydration compared to sodium content. However, it is important to note that the low sodium condition contained half of the sodium of the high sodium conditions, and the beverages were not devoid of electrolytes. From these results as well as our own, there 
is evidence for a limited amount of electrolyte present in the rehydration beverage to be capable of modest rehydration.

While sodium is the primary electrolyte of the extracellular space and has a pronounced role in rehydration [25], potassium, the primary electrolyte of the intracellular space, has demonstrated similar rehydration capabilities [26,27]. Yawata [26] examined the replacement of body fluids in each fluid compartment for sodium and potassium in dehydrated rats. It was observed that sodium preferentially rehydrated the extracellular space and potassium rehydrated the intracellular space. It was also noted that rehydration of the intracellular space took precedence over rehydration of the extracellular space, potentially indicating the relative importance of rehydrating the intracellular space. In the present study, the absolute amount of potassium consumed was similar between the $\mathrm{CE}$ and FW conditions. However, the $\mathrm{AE}$ condition consumed nearly twice as much as the CE and FW conditions, $643.6 \mathrm{mg}$ vs $354.5 \mathrm{mg}$ and $379.3 \mathrm{mg}$, respectively. The current findings indicated less diluted urine 4 hours following dehydration and a USG not significantly different than pre-testing for the $\mathrm{AE}$ condition only. Considering this and the absence of differences observed in percent body weight loss, urine volume, drink volume, or fluid retention, it appears that the $\mathrm{AE}$ beverage favored rehydration of the intracellular space. This is in agreement with Nielsen et al. [27] who observed preferential rehydration of the intracellular space with potassium compared to sodium. Additionally, the aforementioned researchers discovered that sodium increases plasma volume to a greater extent than potassium, which may also explain the differences observed for USG in the present study.

In addition to potassium differences, the $\mathrm{AE}$ beverage contains BCAAs as well as taurine and coconut water powder. While this may be the first study to investigate BCAAs effects on hydration, taurine has been previously examined. Muscles expel taurine during contraction [38,39]. Cuisinier et al. [40] examined plasma taurine levels during exercise in both hydrated and dehydrated states, observing a $32 \%$ greater increase in plasma taurine levels in the hydrated condition. This led researchers to conclude taurine is released due to an osmoregulatory process and to be taken up by other cells which have a role in osmotic regulation. Coconut water has demonstrated efficacy over water yet with mixed results. It has been observed as equal to a CE beverage for rehydration [20,41]. In contrast, Saat et al. [17] have reported greater rehydration effects with a CE beverage, despite the coconut water condition consuming more electrolytes, yet it has been shown as well that the addition of sodium to coconut water increases rehydration [20].

From the present results, it is also possible that carbohydrates were not necessary for rehydration, as no differences between the AE, CE, and FW beverages were observed for fluid retention. Few researchers have examined carbohydrates for rehydration in the absence of electrolytes. However, lambert et al. [42] conducted such comparison and found no significant differences between beverages containing or not containing carbohydrates, concluding that the benefit of carbohydrates is glycogen replenishment and taste, not rehydration. In agreement, varying glucose concentrations had no effect on rehydration when controlling for electrolyte content [43].

Unique to this study, subjects were rehydrated initially with the test beverages using a practical dose and followed up with water to replace $150 \%$ of lost body weight, which may more adequately simulate athletes' common practice. Wherein, an athlete may drink one bottle ( $24 \mathrm{fl} \mathrm{oz} ; 26 \mathrm{fl} \mathrm{oz}$ were used in this study) of a recovery drink then drink water the remainder of the day or several hours thereafter. In this practical model, there were no observed differences in rehydration capability between all test beverages, yet the $\mathrm{AE}$ and $\mathrm{CE}$ beverages were anticipated to rehydrate more adequately than FW, as hypothesized. Therefore, it may be necessary for the dehydrated athlete to drink uncommonly more of an $\mathrm{AE}$ or $\mathrm{CE}$ beverage than they would expect to achieve the results observed in past literature $[16,19,28]$. However, the practicality of ingesting such large amounts of a CE beverage warrants concern as high doses of simple sugars may not be advantageous to all athletes.

The present study provides evidence for electrolytes being the primary determinant of rehydration when ingesting practical/real world volumes, regardless of calorie or macronutrient content. Future research is needed to examine BCAAs effects on rehydration without electrolytes or other confounding factors compared to carbohydrate and/or electrolytes. It may also be of interest to examine recovery of performance following dehydration using an $\mathrm{AE}$ compared to a $\mathrm{CE}$ beverage.

\section{Conclusion}

Overall, there appears to be a potential benefit of a BCAA and/or potassium containing beverage on intracellular hydration. However, it is not clear from the present study which of the two solutes are driving this process. Alternatively, the delivery method of the beverages or the amount of test beverage could have been insufficient to produce anticipated results as reported in past investigations. Presently, we can conclude an EA and potassium supplement enhances the speed of cellular rehydration compared to an EC or FW beverage in healthy men and women after acute dehydration of about $2 \%$ body mass loss, as the $\mathrm{AE}$ urine returned to baseline concentration prior to $\mathrm{CE}$ or FW, yet no differences existed for urine volume, drink volume, or fluid retention. Practical amounts of all beverages used in the current investigation with a total fluid volume 
equal to $150 \%$ of water lost during dehydration all appear to rehydrate. However, baseline urine concentration (USG) was achieved with the same fluid loss at 4 hours post-dehydration for AE only compared to CE and FW. Future studies should look at similar products over a longer rehydration (post-dehydration) period to assess the total volume retained from $\mathrm{CE}$ and FW beverages as the current study suggests more than 3 hours post-rehydration is needed for CE and FW to return to baseline USG values and a greater amount of urine volume (less retention) may be observed compared to a AE beverage similar to the one used in the current investigation.

\section{Abbreviations}

BCAA: Branched chain amino acids; EA: Electrolyte amino acid; EC: Electrolyte carbohydrate; FW: Flavored water; USG: Urine specific gravity.

\section{Competing interests}

$C T, J J, P F, L C, M M, N L, M K$, and JM are employees of the funding source, MusclePharm Corporation. However, JJ, MM, and NL were not employees at the time of data collection, and the remaining authors have no financial interests concerning the outcome of this investigation. Additionally, this publication should not be viewed as endorsement by the investigators, the United States Sports Academy, the University of Northern Colorado, Metropolitan State University of Denver, the University of Nebraska, or MusclePharm Corporation.

\section{Authors' contributions}

$C T, J J, P F, L C, M M, J S, N L, M K$, and JM contributed to conception of experimental design, drafting of the manuscript, and interpretation of data. $C T, P F, L C, J S, S O, C M$, and NL participated in data collection. Additionally, all authors read and approved the final manuscript.

\section{Acknowledgements}

We would like to thank all of the participants for their time and hard work throughout the study.

\section{Author details}

${ }^{1}$ MusclePharm Sports Science Institute, MusclePharm Corp., 4721 Ironton St., Building A, Denver, CO 80239, USA. ²University of Nebraska, Lincoln, NE, USA. ${ }^{3}$ Metropolitan State University of Denver, Denver, CO, USA. ${ }^{4}$ University of Northern Colorado, Greeley, CO, USA. ${ }^{5}$ Department of Sports Exercise Science, United States Sports Academy, Daphne, AL, USA.

Received: 27 March 2014 Accepted: 6 May 2014

Published: 26 May 2014

\section{References}

1. Armstrong $L$, Maresh C: The exertional heat illnesses: a risk of athletic participation. Med Exerc Nutr Health 1993, 2:125-147.

2. Werner J: Temperature regulation during exercise: an overview. Exercise, Heat, and Thermoregulation Dubuque, IA: Brown and Benchmark; 1993:49-77.

3. Sawka MN, Pandolf KB: Effects of body water loss on physiological function and exercise performance. Perspect Exerc Sci Sports Med 1990, 3:1-38.

4. Armstrong LE, Costill DL, Fink WJ: Influence of diuretic-induced dehydration on competitive running performance. Med Sci Sports Exerc 1985, 17:456-461.

5. Bijlani RL, Sharma KN: Effect of dehydration and a few regimes of rehydration on human performance. Indian J Physiol Pharmacol 1980, 24:255-266.

6. Bosco JS, Greenleaf JE, Bernauer EM, Card DH: Effects of acute dehydration and starvation on muscular strength and endurance. Acta Physiol Pol 1974, 25:411-421.

7. Kozlowski S, Brzezinska Z, Kruk B, Kaciuba-Uscilko H, Greenleaf JE, Nazar K: Exercise hyperthermia as a factor limiting physical performance: temperature effect on muscle metabolism. J Appl Physiol 1985 59:766-773.
8. Maughan $\mathrm{R}$, Leiper J: Sodium intake and post-exercise rehydration in man. Eur J Appl Physiol Occup Physiol 1995, 71:311-319.

9. Mnatzakanian PA, Vaccaro P: Effects of $4 \%$ thermal dehydration and rehydration on hematological and urinary profiles of college wrestlers. Ann Sports Med 1984, 2:41-46.

10. Saltin B: Aerobic and anaerobic work capacity after dehydration. $J$ Appl Physiol 1964, 19:1114-1118.

11. Sawka MN, Coyle EF: Influence of body water and blood volume on thermoregulation and exercise performance in the heat. Exerc Sport Sci Rev 1999, 27:167-218.

12. Pichan G, Gauttam RK, Tomar OS, Bajaj AC: Effect of primary hypohydration on physical work capacity. Int J Biometeorol 1988, 32:176-180.

13. Walsh RM, Noakes TD, Hawley JA, Dennis SC: Impaired high-intensity cycling performance time at low levels of dehydration. Int J Sports Med 1994, 15:392-398.

14. Costill DL, Sparks KE: Rapid fluid replacement following thermal dehydration. J App/ Physiol 1973, 34:299-303.

15. Maughan R, Leiper J: 12 Post-Exercise rehydration in man: effects of voluntary intake of four different beverages. Med Sci Sports Exerc 1993, 25:S2.

16. Seifert J, Harmon J, DeClercq P: Protein added to a sports drink improves fluid retention. Int J Sport Nutr Exerc Metab 2006, 16:420-429.

17. Saat $M$, Singh $R$, Sirisinghe $R G$, Nawawi $M$ : Rehydration after exercise with fresh young coconut water, carbohydrate-electrolyte beverage and plain water. J Physiol Anthropol Appl Human Sci 2002, 21:93-104.

18. Millard-Stafford M, Rosskopf LB, Snow TK, Hinson BT: Water versus carbohydrate-electrolyte ingestion before and during a $15-\mathrm{km}$ run in the heat. Int J Sport Nutr 1997, 7:26-38.

19. Watson P, Love TD, Maughan RJ, Shirreffs SM: A comparison of the effects of milk and a carbohydrate-electrolyte drink on the restoration of fluid balance and exercise capacity in a hot, humid environment. Eur J Appl Physiol 2008, 104:633-642.

20. Ismail I, Singh R, Sirisinghe RG: Rehydration with sodium-enriched coconut water after exercise-induced dehydration. Southeast Asian J Trop Med Public Health 2007, 38:769-785.

21. Hamouti N, Fernandez-Elias VE, Ortega JF, Mora-Rodriguez R: Ingestion of sodium plus water improves cardiovascular function and performance during dehydrating cycling in the heat. Scand J Med Sci Sports 2014, 24:507-518. doi: 10.1111/sms.12028.

22. Shirreffs SM, Watson P, Maughan RJ: Milk as an effective post-exercise rehydration drink. Br J Nutr 2007, 98:173-180.

23. Shirreffs SM, Armstrong LE, Cheuvront SN: Fluid and electrolyte needs for preparation and recovery from training and competition. J Sports SCi 2004, 22:57-63.

24. Shirreffs SM, Sawka MN: Fluid and electrolyte needs for training, competition, and recovery. J Sports Sci 2011, 29(Suppl 1):S39-S46.

25. Harries M, Williams C, Stanish WD: Oxford textbook of sports medicine. USA: Oxford University Press; 1996

26. Yawata T: Effect of potassium solution on rehydration in rats: comparison with sodium solution and water. Jpn J Physiol 1990, 40:369-381.

27. Nielsen B, Sjogaard G, Ugelvig J, Knudsen B, Dohlmann B: Fluid balance in exercise dehydration and rehydration with different glucose-electrolyte drinks. Eur J Appl Physiol Occup Physiol 1986, 55:318-325.

28. Maughan RJ, Owen JH, Shirreffs SM, Leiper JB: Post-exercise rehydration in man: effects of electrolyte addition to ingested fluids. Eur J Appl Physiol Occup Physiol 1994, 69:209-215

29. Brouns F, Kovacs EM, Senden JM: The effect of different rehydration drinks on post-exercise electrolyte excretion in trained athletes. Int J Sports Med 1998, 19:56-60.

30. Maughan RJ, Leiper JB, Shirreffs SM: Factors influencing the restoration of fluid and electrolyte balance after exercise in the heat. Br J Sports Med 1997, 31:175-182

31. Elliot TA, Cree MG, Sanford AP, Wolfe RR, Tipton KD: Milk ingestion stimulates net muscle protein synthesis following resistance exercise. Med Sci Sports Exerc 2006, 38:667-674.

32. Norton LE, Layman DK: Leucine regulates translation initiation of protein synthesis in skeletal muscle after exercise. J Nutr 2006, 136:533S-537S

33. Norton LE, Wilson GJ, Layman DK, Moulton CJ, Garlick PJ: Leucine content of dietary proteins is a determinant of postprandial skeletal muscle protein synthesis in adult rats. Nutr Metab (Lond) 2012, 9:67. 
34. Sawka MN, Burke LM, Eichner ER, Maughan RJ, Montain SJ, Stachenfeld NS, American College of Sports M: American College of Sports Medicine position stand. Exercise and fluid replacement. Med Sci Sports Exerc 2007, 39:377-390.

35. Marchesini G, Marzocchi R, Noia M, Bianchi G: Branched-chain amino acid supplementation in patients with liver diseases. J Nutr 2005, 135:1596S-1601S.

36. Casa DJ, Armstrong LE, Hillman SK, Montain SJ, Reiff RV, Rich BS, Roberts WO, Stone JA: National athletic trainers' association position statement: fluid replacement for athletes. J Athl Train 2000, 35:212-224.

37. Mitchell JB, Phillips MD, Mercer SP, Baylies HL, Pizza FX: Postexercise rehydration: effect of $\mathrm{Na}(+)$ and volume on restoration of fluid spaces and cardiovascular function. J Appl Physiol 2000, 89:1302-1309.

38. Graham TE, Kiens B, Hargreaves M, Richter EA: Influence of fatty acids on ammonia and amino acid flux from active human muscle. Am J Physiol 1991, 261:E168-E176.

39. Graham TE, Turcotte LP, Kiens B, Richter EA: Training and muscle ammonia and amino acid metabolism in humans during prolonged exercise. $J$ Appl Physiol 1995, 78:725-735.

40. Cuisinier C, Michotte De Welle J, Verbeeck RK, Poortmans JR, Ward R, Sturbois $X$, Francaux M: Role of taurine in osmoregulation during endurance exercise. Eur J Appl Physiol 2002, 87:489-495.

41. Kalman DS, Feldman S, Krieger DR, Bloomer RJ: Comparison of coconut water and a carbohydrate-electrolyte sport drink on measures of hydration and physical performance in exercise-trained men. $J$ Int Soc Sports Nutr 2012, 9:1.

42. Lambert CP, Costill DL, McConell GK, Benedict MA, Lambert GP, Robergs RA, Fink WJ: Fluid replacement after dehydration: influence of beverage carbonation and carbohydrate content. Int I Sports Med 1992, 13:285-292.

43. Evans GH, Shirreffs SM, Maughan RJ: Postexercise rehydration in man: the effects of carbohydrate content and osmolality of drinks ingested ad libitum. Appl Physiol Nutr Metab 2009, 34:785-793.

doi:10.1186/1475-2891-13-47

Cite this article as: Tai et al:: An amino acid-electrolyte beverage may increase cellular rehydration relative to carbohydrate-electrolyte and flavored water beverages. Nutrition Journal 2014 13:47.

\section{Submit your next manuscript to BioMed Central and take full advantage of:}

- Convenient online submission

- Thorough peer review

- No space constraints or color figure charges

- Immediate publication on acceptance

- Inclusion in PubMed, CAS, Scopus and Google Scholar

- Research which is freely available for redistribution 